\title{
Hotelaria de Luxo: como elementos visuais do ambiente estimulam a expectativa das experiências extraordinárias
}

\section{Luxury Hospitality: how environmental visual components stimulate the expectancy of extraordinary experiences}

\author{
Alan Machado Gomes (GOMES, A. M.)* \\ Viviane Santos Salazar (SALAZAR, V. S.) ${ }^{* *}$ \\ Yákara Vasconcelos Pereira Leite (LEITE, Y. V. P.) ${ }^{* * *}$
}

\begin{abstract}
RESUMO - O presente trabalho teve como objetivo analisar como hotéis de luxo utilizam elementos visuais para criar ambientes que permitam estimular a expectativa da experiência extraordinária. A pesquisa destaca que a utilização de determinados elementos no ambiente interferem positivamente na experiência de consumo do cliente. Com uma natureza qualitativa, a pesquisa optou por um método de análise visual. Dois hotéis de luxo foram selecionados e desses hotéis, três ambientes internos foram analisados por meio de fotografias encontradas nos sites das respectivas empresas. Para a análise dos dados, foram estabelecidos critérios como arquitetura, decoração, layout, mobiliário, cores, iluminação e elementos presentes no ambiente, previamente testados por outros pesquisadores. Os resultados obtidos indicam que elementos visuais do ambiente estimulam a visão e a expectativa das experiências extraordinárias.
\end{abstract}

Palavras-chave: Hotelaria; Marketing de Serviços; Luxo.

ABSTRACT - This study aimed to analyze how luxury hotels use the visual elements to create environments that enable to stimulate the expectation of a extraordinary experience. The research highlights that the use of certain elements in the environment affect positively the consumer experience. With a qualitative nature, the study opted for a method of visual analysis. Two luxury hotels were selected and of these hotels, three indoor environments were analyzed by pictures found in their websites. For data analysis, some criteria were established as architecture, decoration, layout, furnishings, colors, lighting and some elements present in the places, previously tested by other researchers. The results indicate that visual elements of the environment stimulate the vision and the expectation of a extraordinary experiences.

Key words: Hospitality; Service Marketing; Luxury.

Graduação em Hotelaria pela Universidade Federal de Pernambuco (UFPE). Endereço para correspondência: Departamento de Hotelaria e Turismo (UFPE). Av. Prof. Moraes Rego, 1235 - Cidade Universitária. CEP: 50670-901 - Recife - Pernambuco (Brasil). Telefone: (81) 2126-8000. E-mail: alanhotel@gmail.com

** Graduação em Hotelaria, Mestrado em Administração e Doutoranda em Administração pela Universidade Federal de Pernambuco (UFPE). Professora do curso de Hotelaria (UFPE). Endereço para correspondência: Departamento de Hotelaria e Turismo (UFPE). Av. Prof. Moraes Rego, 1235 - Cidade Universitária. CEP: 50670-901 - Recife - Pernambuco (Brasil). Telefone: (81) 2126-8000. E-mail: viviane_salazar@yahoo.com.br

*** Graduação, Mestrado e Doutorado em Administração pela UFPE. Coordenadora e Professora de Administração da Universidade Federal Rural do Semi-Árido (UFERSA). Endereço para correspondência: Av. Francisco Mota, 572 (Bairro: Costa e Silva). CEP: 59.625-900 - Mossoró - Rio Grande do Norte (Brasil). E-mail: yakarav@gmail.com 


\section{INTRODUÇÃO}

No início do século XX, começaram a ocorrer algumas modificações no cenário econômico mundial. Uma delas esteve relacionada à forma de consumo, pois as pessoas estavam habituadas a consumir o que satisfazia apenas suas vontades vitais, frustrando muitas vezes suas necessidades relativas (ALLÉRÈS, 2006). Essa situação, porém, não se manteve estagnada. Com a melhoria dos padrões de vida da população, o acesso a bens e serviços, até então tidos como supérfluos, ficou maior possibilitando o consumo de bens de luxo.

O luxo se presta a definições subjetivas e está presente em inúmeras categorias de produtos e serviços, como: roupas, acessórios de moda, cosméticos, perfumes, jóias, carros, relógios, acessórios de viagem, peles, objetos de decoração, hotéis, cruzeiros marítimos, bebidas, comidas e spas. Na visão de Alléres (2006), alguns fatores são essenciais para que se defina um produto como "de luxo", um deles é a diferenciação, tanto do bem em si, quanto de quem o usa, e o seu consequente simbolismo de status social. Outro fator é o apelo dos sentidos, como atributos de beleza, toque agradável, bom cheiro, sons harmoniosos de forma a criar uma experiência hedônica (GALHANONE, 2005).

Dentre os produtos de luxo destacam-se os serviços de lazer e mais especificamente os serviços hoteleiros. Para Lipovetsky e Roux (2005), todos os hotéis luxuosos acomodam locais de restabelecimento e serviços especiais, atendendo aos anseios dos seus hóspedes. Uma das formas de se diferenciar é a utilização do marketing sensorial, pois, o luxo, enquanto emblema de beleza, de bom gosto e refinamento, foi frequentemente relacionado aos prazeres dos cinco sentidos (LIPOVETSKY; ROUX, 2005).

Ao considerar a atmosfera de uma organização de serviço, Petr (2002) afirma que características físicas e visíveis do quadro da experiência, como a decoração de um local, por exemplo, podem determinar as características de posicionamento de um ambiente. Os aspectos concretos e físicos do lugar contribuem para uma forte coerência da imagem comercial de uma empresa (HETZEL, 2000). Para complementar esse ambiente, aspectos sensoriais ajudam a criar uma identidade simbólica do local (BARBOSA, 2006). O marketing sensorial que trata dos cinco sentidos do ser humano 
relaciona-se às experiências vividas pelos clientes e estas experiências possuem dimensões sensoriais, emocionais, cognitivas, racionais e funcionais (TEIXEIRA, 2007).

Levando-se em conta a crescente demanda de produtos e serviços de luxo no mundo, e da hotelaria, como integrante desse mercado, que acompanha um processo de transformações marcantes, foi escolhido o ambiente dos hotéis de luxo para analisar como questões sensoriais - mais especificamente da visão - são capazes de permitir o estímulo das experiências extraordinárias. Diante do exposto surgiu a pergunta de pesquisa que orientou este trabalho: Como hotéis de luxo utilizam os elementos visuais presentes no ambiente para criar ambientes que permitam estimular a expectativa das experiências extraordinárias?

\section{O MERCADO DE LUXO DOS HOTÉIS}

Allérès (2006) afirma que, comumente, o termo "prestígio", do latim praestigium, é utilizado no lugar do termo luxo, por ter uma conotação mais positiva, e significa ilusão. Porém, apesar do uso especulativo e depreciativo da palavra luxo, ela é a única que representa melhor a extensão das qualidades dos bens que a inclui. Por isso, o termo luxo é este cuja definição envolve, ao mesmo tempo, as especificidades dos bens de prestígio e a dos produtos de alto nível (ALLÉRES, 2006). Ainda sobre o conceito de luxo, este se presta a definições subjetivas, e está cada vez mais presente em inúmeras categorias de produtos e serviços (GALHANONE; TOLEDO, 2008) como os hotéis.

Os primeiros hotéis de negócios eram empreendimentos de luxo, localizados nos centros financeiros das grandes cidades, junto aos mais importantes estabelecimentos públicos e empresas, inseridos na principal atração turística de um local (ANDRADE, 2003). No Brasil, o princípio da hotelaria de luxo se deu em 1966 com a criação da então Empresa Brasileira de Turismo - EMBRATUR (atual Instituto Brasileiro do Turismo) e, junto a ela, o FUNGETUR (Fundo Geral do Turismo), que por meio de incentivos fiscais, fomentaram a implantação de hotéis, promovendo uma nova fase na 
hotelaria brasileira, principalmente no segmento de hotéis de luxo, os chamados cinco estrelas (ANDRADE, 2003).

Uma das estratégias de diferenciação proposta por Castelli (1991) para os meios de hospedagem é por meio da arquitetura e decoração. Os elementos do ambiente de serviços presentes no hotel, por sua vez, precisam ser convergentes de modo a criar uma atmosfera que provoque reações específicas nos consumidores.

\section{AMBIENTE DE SERVIÇOS E MARKETING SENSORIAL}

Pelo fato de um serviço ser geralmente produzido e consumido simultaneamente, o consumidor desse tipo de atividade está "na fábrica de serviços" e esta tem um forte impacto na sua percepção da experiência (BITNER, 1992). Para Rieunier (2004) a atmosfera de um ambiente é entendida como todos os elementos que podem ser controlados a fim de influenciar as reações afetivas, cognitivas, físicas ou comportamentais dos indivíduos - que incluem tanto os clientes quanto os funcionários, sendo descrita em termos sensoriais através da visão, audição, aroma e tato.

A partir de pesquisas sobre a atmosfera de um ambiente se desenvolveu a corrente do marketing sensorial, que busca uma gestão efetiva dos fatores da atmosfera do ponto de venda (música, perfumes, cores, sensações táteis e gustativas) com o objetivo de suscitar no consumidor as reações afetivas, cognitivas e comportamentais favoráveis à atividade de compra (RIEUNIER, 2004). O marketing sensorial une-se às experiências vividas pelos consumidores, que vão além dos aspectos funcionais dos produtos e/ou serviços (KOEHL, 2004). Para Schmitt e Simonson (2002), uma organização pode usar o marketing sensorial para diferenciar a si mesma e a seus produtos no mercado, para motivar os clientes a comprar os seus produtos e para transmitir valores aos clientes.

Pode-se dizer que os estímulos sensoriais de um ambiente físico, por exemplo, têm o potencial de desencadear uma rede de significações e constituir uma experiência única ou extraordinária para cada indivíduo, assunto esse que é tratado abaixo. 


\section{EXPERIÊNCIAS DE CONSUMO EXTRAORDINÁRIAS}

Atualmente, os consumidores querem mais do que produtos ou serviços, eles desejam viver experiências que estimulem os sentidos e mexam com suas emoções (SCHMITT; SIMONSON, 2002). As experiências são acontecimentos individuais que ocorrem como resposta a algum estímulo e geralmente são o resultado de uma observação direta e/ou de participação nos acontecimentos, sejam eles reais, virtuais ou imaginários.

De acordo com Barbosa (2006) as experiências podem ser classificadas em um contínuo que vai da experiência ordinária à extraordinária, nesse sentido, os fatores relacionados à demanda parecem diferentes quando comparados a um serviço ordinário (utilitário) com uma experiência extraordinária (hedônica). Além disso, considera que o primeiro fornece ao consumidor benefícios, tais como: rapidez, conveniência e preço mais baixo. Já a experiência extraordinária se caracteriza como um tipo de sensação. Os estabelecimentos que tentam fazer com que seus clientes vivam experiências de consumo encantadoras têm que oferecer algo mais. A qualidade do serviço, o preço, o acompanhante e a atmosfera são outros fatores essenciais que poderão complementar essa experiência (BARBOSA, 2006).

Os bens de luxo são os que mais se aproximam de um significado simbólico máximo, com uma importância relativa bem menor da sua função utilitária (STREHLAU, 2004). Corroborando este pensamento, Lipovetski e Roux (2005) afirmam que muitos precedentes consideravam o luxo emblema de beleza, bom gosto e refinamento, frequentemente associados aos prazeres dos cinco sentidos. Portanto, percebe-se a relação do luxo com experiências extraordinárias e a ativação dos cinco sentidos, em um determinado ambiente. Os hotéis de luxo parecem se apresentar como ambiente propício para estudar como os elementos do ambiente podem estimular a expectativa das experiências extraordinárias dos clientes.

\section{MÉTODO DA PESQUISA}

O objetivo deste trabalho foi analisar ambientes de hotéis de luxo que se utilizam de uma concepção sensorial, com foco na visão, para tornar a experiência de consumo 
algo extraordinário. Com isso, o método escolhido para conduzir esta pesquisa foi do tipo qualitativo, com o uso da análise visual de fotografias.

Diante da natureza qualitativa desta pesquisa, optou-se pela abordagem de estudo da pesquisa visual. Para Heisley e Levy (1991), a pesquisa visual conquistou momentos de naturalidade na pesquisa qualitativa de marketing pela sua eficiência em explicar fatores subjetivos do consumidor.

A escolha desse método de pesquisa se deu pelo fato da capacidade e da imagem fotográfica conterem informações de maneira econômica e confiável, tornando possível uma catalogação mais eficiente de dados nas pesquisas. Porém, esses métodos visuais são pouco adotados em pesquisas qualitativas em marketing (MENDONÇA; BARBOSA; DURÃO, 2007).

Segundo Hutton e Richardson (1995 apud MENDONÇA; BARBOSA; DURÃO, 2007) ${ }^{1}$, o marketing de serviços, ao qual se refere na pesquisa, pode valer-se do registro das evidências físicas para o envio de mensagens fortes que ajudem a estabelecer a imagem da empresa e afetar expectativas dos consumidores. Os mesmos autores, com relação aos elementos visuais tangíveis, apontam que esses elementos costumam ser citados pelos consumidores com muito mais frequência do que os demais atributos determinantes de satisfação e da qualidade do serviço prestado. Portanto, nota-se a importância desses elementos visuais no contexto da organização.

Considerando o objetivo central desta pesquisa, foram selecionados dois hotéis de luxo, ambos fazendo parte de uma rede internacional de hotéis de luxo, o chamado Leading Hotels of the World (LHW). Um deles localizado na cidade de São Paulo, o Fasano; e o outro, localizado em Buenos Aires, o Faena Hotel. Ressalta-se que pelo fato das informações estarem expostas em sites, isso as tornam públicas, não interferindo na divulgação dos seus nomes.

O Fasano teve sua origem com o secular restaurante de cozinha italiana, homônimo ao hotel, e fica localizado no bairro dos Jardins, vizinho de grifes luxuosas mundialmente renomadas (HOTEL FASANO, 2009). Com uma decoração que recria com uma roupagem arrojada o estilo dos anos 30, o Fasano tem uma arquitetura que une a contemporaneidade do design com detalhes clássicos, como móveis de época e tijolos

\footnotetext{
${ }^{1}$ HUTTON, J. D.; RICHARDSON, L. D. Healthscape: the role of the facility and physical environment on consumer attitudes, satisfaction, quality, assessments and behaviors. Health Care Management Review, v. 20, n. 2, p. 48-61, 1995.
} 
ingleses na fachada (HOTEL FASANO, 2009). Além disso, o seu gestor, Rogério Fasano, atento aos detalhes, é referência brasileira como ícone de luxo, de acordo com o consultor do mercado de luxo, Carlos Ferreirinha (OLIVEIRA, 2009).

Cinco estrelas design de Puerto Madero, na capital argentina, o Faena dispõe de suítes luxuosas, unindo o passado histórico de sua cidade com o presente vibrante (LHW, 2009). De acordo com Faena Universe (2009) o hotel também possui uma vasta lista de premiações internacionais, como por exemplo, o título de cinco diamantes da American Academy of Hospitality Sciences, e melhor ambientação e design do guia Cond Nast Traveller UK's Gold List.

A escolha desses hotéis se deu por serem dois estabelecimentos de referência no serviço prestado ao cliente e oferecerem uma riqueza de detalhes na sua decoração. Os ambientes selecionados foram os quartos, as áreas de convívio e os principais restaurantes de ambos os hotéis. O motivo da escolha de três ambientes distintos foi o de ampliar a visão sobre os locais selecionados para estudo, além de analisar a coerência entre esses ambientes, como sugere Cottet, Plichon e Lichtle (2007). Em pesquisas em que a fotografia é utilizada como instrumento de coleta de dados pode-se fazer uso de imagens preexistentes ou o pesquisador pode ele mesmo produzir as imagens que serão analisadas (MENDONÇA; BARBOSA; DURÃO, 2007). Para a presente pesquisa, a utilização do método visual mencionada neste artigo é composta por fotos de duas organizações, extraídas dos sites na internet das próprias empresas na web. Para a análise dos dados, com base no referencial teórico, foram criadas categorias analíticas e os construtos foram estabelecidos para dar suporte às análises da pesquisa.

\section{ANÁLISE DOS DADOS DA PESQUISA}

Para análise dos dados, foram utilizados os seguintes critérios previamente testados por outros pesquisadores (MENDONÇA; BARBOSA; DURÃO, 2007; ZEITHAML; BITNER, 2003): arquitetura interna e decoração; layout; móveis e equipamentos; iluminação; cores; sinais, símbolos e objetos. Foram analisadas as fotos dos quartos, dos lobbies e dos restaurantes.

As fotos são de três ambientes internos: quarto, área de convívio e restaurante, em que todas essas fotografias foram obtidas dos sites da internet dos respectivos 
estabelecimentos. Tendo as fotos como centro da pesquisa, foram analisadas as similaridades e diferenças dos ambientes retratados. Assim, foi possível verificar o que diferenciava esses hotéis e como esses ambientes são capazes de tornar uma experiência em extraordinária.

O ambiente de serviço para Mendonça, Barbosa e Durão (2007) afeta a percepção e o comportamento dos clientes e, consequentemente, sua satisfação e avaliação da qualidade. Por isso é importante conhecer quais as características do ambiente de serviços que podem influenciar a percepção dos consumidores. Para isso, a pesquisa buscou verificar nas imagens essas características ambientais, capazes de influenciar o comportamento dos clientes.

\subsection{ARQUITETURA INTERNA E DECORAÇÃO}

Uma instalação bem ou mal projetada, do ponto de vista do cliente, pode ser uma experiência prazerosa ou não (ZEITHALM; BITNER, 2003). Almeida et al. (2007) complementam mencionando que em termos práticos, o que se espera de um hotel de luxo são instalações amplas, bem cuidadas e conservadas, que primam pelo uso de materiais naturais e ambientação coerente com a proposta do hotel, tanto nas áreas comuns quanto nos apartamentos. Nos ambientes dos hotéis em análise, pode-se perceber essa coerência na arquitetura interna e decoração de seus ambientes.

O Faena apresenta uma decoração vibrante com elementos de design, onde o vermelho aparece em destaque em meio ao branco (foto 1). Já a decoração mais clássica do Fasano, também mixado com elementos de design moderno cria um aspecto de sofisticação e discrição (foto 2).
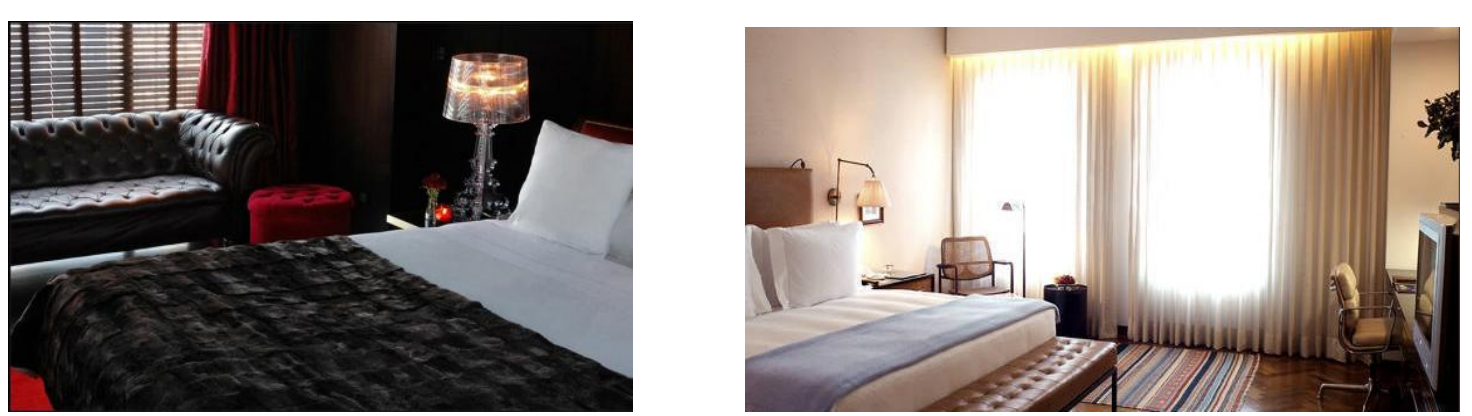

FOTOS 1 e 2 - AMBIENTE INTERNO DO QUARTO DO HOTEL FAENA E DO HOTEL FASANO SÃO PAULO (RESPECTIVAMENTE).

Fontes: Faena Universe (2009) e Hotel Fasano (2009). 


\subsection{LAYOUT}

Alguns símbolos desempenham papel de importância bastante expressiva na embalagem dos serviços, um desses símbolos é o layout dos ambientes, que auxilia na formação de opinião dos consumidores (LAS CASAS, 2000). Para o layout do apartamento, considerando sempre o tipo de hotel e os tipos de hóspedes a que se destina, Andrade (2003) sugere que devem ser observados alguns requisitos relacionados ao conforto do hóspede, como por exemplo: iluminação adequada a várias situações de uso pelos hóspedes - trabalho, leitura e convívio; correta escolha do mobiliário (dimensões, materiais e design), em função das dimensões do apartamento e do tratamento das superfícies de pisos, paredes e tetos.

No apartamento do Fasano (foto 2), verifica-se o posicionamento em diferentes pontos de luz do apartamento, além da iluminação natural pelas janelas, o que ajuda o ocupante em diversas situações, já com relação ao televisor, não apresenta rotação para diversas direções do quarto. No conjunto, o apartamento se apresenta bem distribuído, com móveis compatíveis com o tamanho da unidade habitacional e materiais coerentes, causando um ambiente harmonioso.

No Faena, a foto 1 apresentada não mostra muito da totalidade do quarto, mas consegue-se observar que o ambiente parece relativamente pequeno em relação à mobília disposta e a presença de luminária em apenas um ponto, poderá ser vista como negativa para clientes que preferem ler em outros ambientes do quarto, senão na cama.

\subsection{MÓVEIS E EQUIPAMENTOS}

Ferrara (2002) aponta um hotel como um dos lugares memoráveis dentro do circuito das viagens, classificando-o como lugar de fetiche e mitificação, no qual se vive uma realidade de superabundância de imagens envolventes. Um dos elementos presentes no ambiente de um hotel de luxo capaz de envolver o cliente é a mobília, tendo a capacidade de influir na formação de opinião dos hóspedes de um hotel (LAS CASAS, 2000).

Ambos os hotéis, como demonstrado pelas fotos, conseguem externar sua exclusividade, desde o desenho empregado na mobília, como a cor. Apresentam 
também outros assentos como sofás, bancos e cadeira de leitura, que valorizam o local e tornam o ambiente aparentemente mais confortável.

A riqueza de texturas do apartamento do Faena (foto 1) é notada pela gama de matéria-prima utilizada como o couro no sofá, a pele na colcha, o liso dos lençóis, a parede de madeira e da persiana, o veludo do assento vermelho, a textura das rosas no criado-mudo e o contraste do liso e rugoso do abajour, tudo combinado criando um ambiente de luxo.

A utilização da madeira no ambiente emana o conforto e o aconchego da natureza (HOTELNEWS, 2009). A presença de madeira nos ambientes das fotografias é abundante e não só como piso, mas também em paredes e utensílios dos dois hotéis. Além da madeira, elementos com couro, flores ou vasos de plantas igualmente trazem o requinte proveniente da natureza e também está presente na maioria dos ambientes selecionados.

\subsection{ILUMINAÇÃO}

A luz, segundo Castelnou (2003), é a primeira e mais importante experiência visual do ser humano, podendo ser direta, indireta ou difusa. Tirar partido da luz sempre foi um elemento da arquitetura, uma vez que o uso de beirais, persianas e outros elementos da arquitetura permitem explorar esteticamente os níveis de iluminação de um ambiente. Na suíte do Faena, é possível ver essa variedade de iluminação, seja pela persiana, a luz difusa do abajour e da luz da vela (foto 1).

Geralmente, os produtos se apresentam melhor com uma iluminação atraente (GOBÉ, 2002). Analisando os restaurantes dos hotéis, pode-se ver que o do Fasano (foto 3) se utiliza mais dos efeitos de iluminação, até por oferecer um ambiente com cores mais escuras, ausência de janelas e um pé direito mais alto. Em função disso, são utilizadas luzes nas paredes, causando um efeito decorativo, além de pequenas luminárias sobre as mesas para facilitar leitura de cardápio e análise das iguarias servidas. Considera-se que o clima criado pela iluminação do restaurante do Fasano torna o local mais aconchegante e sofisticado, uma proposta diferente da do ambiente do Faena (foto 4), que não aparenta necessidade de muita iluminação artificial, devido as 
suas grandes janelas ao fim do restaurante e da utilização abundante da cor branca, criando um local moderno, clean e instigante.

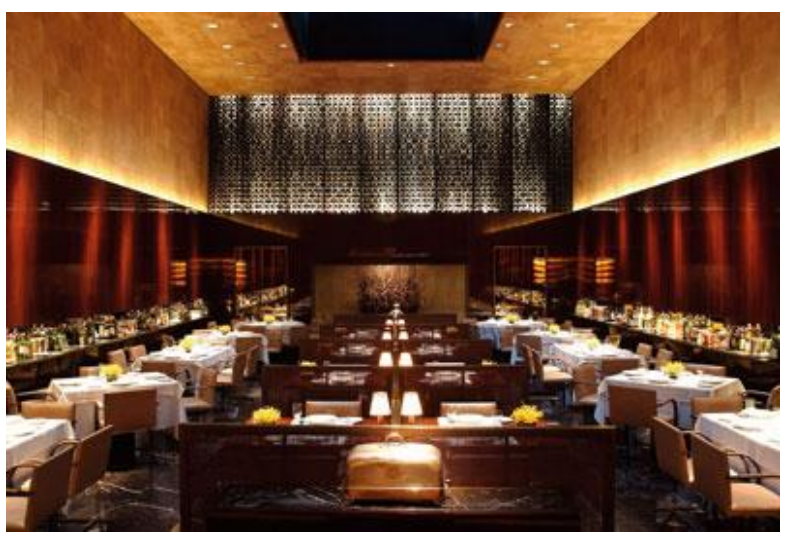

FOTO 3 - AMBIENTE DO RESTAURANTE FASANO Fonte: Hotel Fasano (2009).

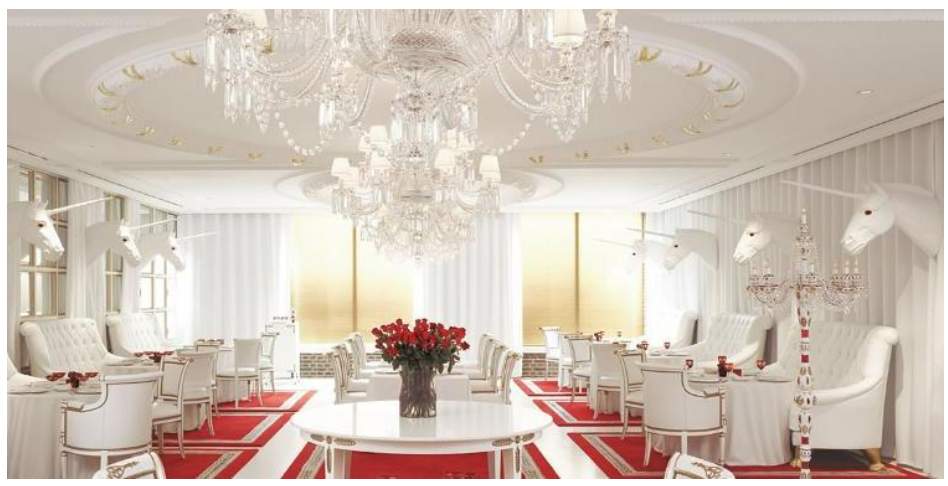

FOTO 4 - RESTAURANTE EL BISTROT, LOCALIZADO NO HOTEL FAENA Fonte: Faena Universe (2009).

\subsection{CORES}

O efeito das cores é estimulado pela aculturação e pela fisiologia, e essas influências se reforçam entre si. Por exemplo, as cores de longo comprimento de onda são estimulantes, o vermelho é a cor de maior estímulo, atraindo o olhar mais rapidamente que outras cores (GOBÉ, 2002). O Faena se utiliza bastante da cor vermelha em seus ambientes e consegue com isso estimular o hóspede. Nos três ambientes selecionados, o vermelho aparece em destaque. Para Gobé (2002), o vermelho proporciona um ambiente emotivo, algo que influi diretamente no homem, um ser sentimental com "lampejos" de racionalidade. É esse alto nível de intensidade 
emocional, que faz com que uma experiência torne-se extraordinária (ARNOULD; PRICE, 1993 apud BARBOSA, 2006) $)^{2}$.

A proposta do Fasano com suas cores mais calmas e de forma criativa possui outra predominância de cores. Para Gobé (2002), o laranja real é amistoso, matizes pastéis são gentis, amarelo alaranjado é receptivo e o azul pálido implica calma. Essas cores são exatamente as predominantes no quarto desse hotel, como os tecidos usados na cama, no tapete e nas cores das cadeiras. $\mathrm{O}$ amarelo alaranjado, cor predominante na imagem da área de convívio do estabelecimento (foto 5) - citado por esse autor como receptivo - é percebido pelo reflexo da iluminação nas cadeiras de couro e nas paredes de madeira, criando um clima de boas vindas ao hóspede que acaba de chegar.

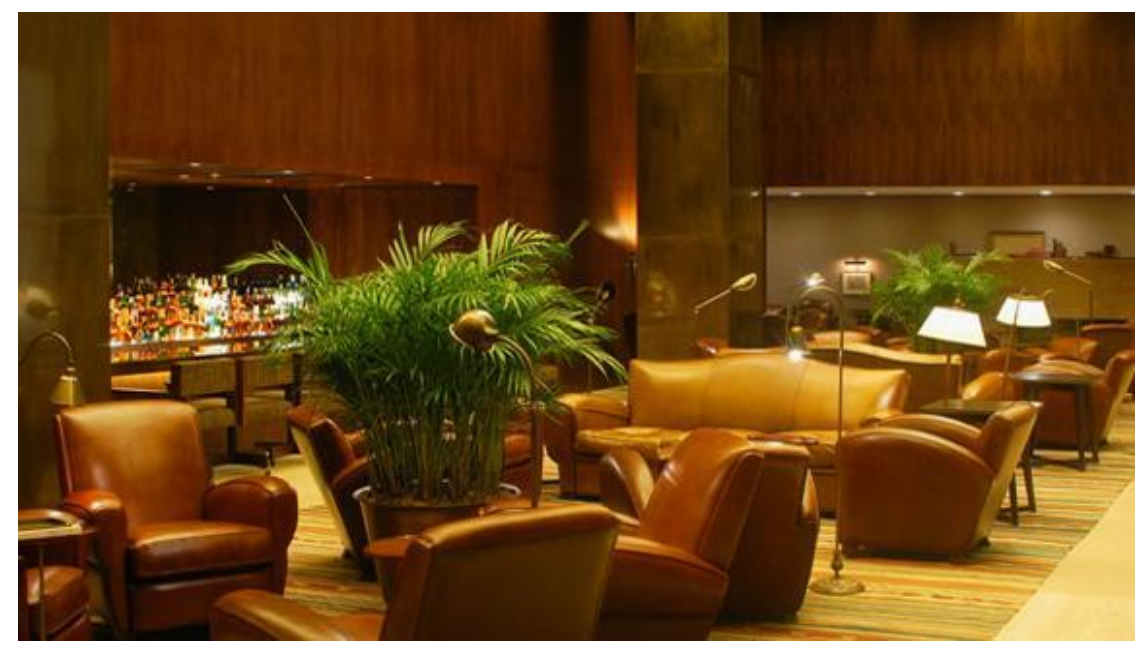

FOTO 5 - AMBIENTE DE CONVÍVIO DO HOTEL FASANO SÃO PAULO Fonte: Hotel Fasano (2009).

Portanto, as cores mais neutras nos apartamentos do Fasano, como os tons pastéis de azul, o bege e branco prevalecendo dão mais sobriedade ao ambiente, tornando o local mais tranquilo. Já no Faena (foto 6), pode-se observar a presença de cores vibrantes como o vermelho em diferentes tonalidades, o preto, o amadeirado da parede e o marrom na textura do couro no sofá. Em ambas as figuras, o conjunto parece harmonioso e positivo, porém o primeiro transmite uma idéia de relaxamento e o segundo de ânimo e vivacidade.

${ }^{2}$ ARNOULD, E. J.; PRICE, L. L. River magic: Extraordinary experience and the extended service encounter. The Journal of consumer research, v. 20, n. 1, p. 24-55, 1993. 


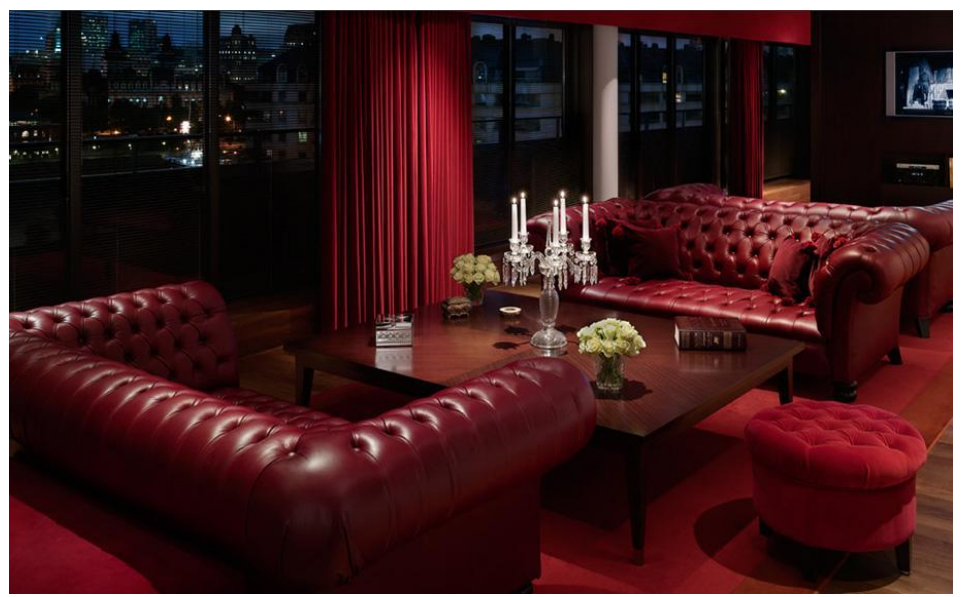

FOTO 6 - AMBIENTE DE CONVÍVIO DO HOTEL FAENA

Fonte: Hotel Faena (2009).

\subsection{SINAIS, SÍMBOLOS E OBJETOS}

Gagliardi (2002) defende que nas organizações contemporâneas os espaços físicos estão vinculados a artefatos, pois as organizações, em geral, são receptivas aos recursos que possam melhorar a sua eficiência. Muitos itens no ambiente físico servem para comunicar sinais implícitos ou explícitos do local para os seus consumidores. Símbolos ou sinais dispostos no interior de um ambiente, como placas ou sinaleiras são exemplos de comunicadores explícitos (BITNER, 1992).

No caso das fotos selecionadas, localizam-se os símbolos mais implícitos. Qualidade dos materiais utilizados na construção, presenças de peças de arte, certificados, tapetes e alguns objetos dispostos no ambiente, podem comunicar significados simbólicos e fazer com que no caso, o hóspede, tenha uma impressão geral do ambiente (BITNER, 1992).

Quando se analisa um restaurante, pela iluminação, talheres dispostos, toalha de mesa branca, subentende-se que o serviço seja completo e não um fast-food. Os restaurantes dos dois hotéis, embora cada um no seu estilo, ambos apresentam-se visualmente como restaurantes refinados pelos elementos e objetos dispostos nas mesas e no ambiente como um todo.

Por fim, é essa atenção aos detalhes e a coerência do ambiente com o que é ofertado é que faz com que esses estabelecimentos criem uma experiência de consumo, não somente utilitária, mas que transmite para o hóspede a sensação de prazer e emoção possibilitando tornar essa experiência extraordinária. 
Assim, nesta pesquisa a análise de conteúdo auxiliou na interpretação dos dados obtidos por meio da análise das fotografias, considerando-se que possibilitou chegar a resultados expressivos e confiáveis, justificando a utilização desta técnica.

\section{CONSIDERAÇÕES FINAIS}

O consumo de luxo, seja um bem ou serviço, está relacionado a objetos tangíveis como uma joia adquirida ou a mobília do hotel em que um cliente está hospedado, porém algo de maior importância para os clientes desse mercado específico, são as emoções, símbolos e sensações causadas por esse consumo.

Os detalhes visuais como cores e suas combinações harmoniosas, a iluminação correta em cada superfície, uma decoração coerente com a proposta do empreendimento ou o mobiliário e equipamentos que se encaixem no contexto do local são de importância expressiva para a satisfação do cliente. Afinal, o primeiro detalhe a se notar ao adentrar um ambiente é o aspecto visual.

Todos esses elementos, causam no indivíduo sensações, sejam elas favoráveis ou não. A intenção vinculada a um hotel de luxo é justamente fornecer sensações positivas nos hóspedes, mesmo sendo de formas distintas. No caso do Hotel Fasano, analisado no estudo, esses elementos do ambiente transmitem a ideia de luxo, sofisticação e serenidade. O hotel Faena busca ativar ainda mais os sentidos, com a presença de cores fortes e contrastantes, mobília mais tradicional em harmonia com objetos mais modernos e contrastes do claro com o escuro. A opção por esse estilo mais sensual e arrojado pode ser justamente para se diferenciar de hotéis de luxo mais tradicionais, atingindo públicos distintos ou até um mesmo público com intenções momentâneas diferentes.

Ainda com relação aos aspectos visuais dos ambientes dos hotéis analisados, sejam das áreas de convívio, dos restaurantes ou dos quartos, considerou-se que todos possuem características determinantes para a formação de um ambiente favorável para o cliente de luxo. Os detalhes e a qualidade dos produtos se fizeram presentes em todos as fotografias estudadas seja na iluminção, na utilização de materiais refinados, na combinação de cores, mobiliário e na forma como esses elementos se apresentam dispostos no ambiente. 


\section{REFERÊNCIAS}

ALLÉRÈS, D. Luxo... Estratégias/Marketing. Rio de Janeiro: Editora FGV, 2006.

ALMEIDA, C. A.; FERREIRA, G. F.; MOTTA, A.; MOYSES, J. M. Conceituação de hotéis exclusivos. Revista Acadêmica Observatório de Inovação do Turismo, v. II, n. 4, p. 1-13, 2007.

ANDRADE, N. Hotel: planejamento e projeto. 6. ed. São Paulo: Editora Senac São Paulo, 2003.

BARBOSA, M. de L. A. Bem-vindo a uma Experiência Extraordinária: Proposições para uma Interpretação sobre o Consumo de Serviços. In: Anais... EMA 2006. Rio de Janeiro, EMA - ENCONTRO DE MARKETING. ANPAD. 2006, p. 1-16.

BITNER, M. J. Servicescape: The impact of physical surroundings on customer and employees. Journal of Marketing, v. 56, n. 2, p. 57-71, 1992.

CASTELLI, G. Marketing hoteleiro. Caxias do Sul: Educs, 1991.

CASTELnOU, A. M. N. Sentindo o espaço arquitetônico: Feeling the architetonic space. Desenvolvimento e Meio Ambiente, n. 7, p. 145-154, jan./jun. Editora UFPR, 2003.

COTTET, P.; PLICHON, V.; LICHTLE, M. C. The compared influence of various perceived environment components : an exploratory study. In: Anais... THE LA LONDE CONFERENCE IN MARKETING COMMUNICATIONS AND CONSUMER BEHAVIOR, junho de 2007, p. 211-221.

FAENA UNIVERSE. Disponível em: <http://www.faenahotelanduniverse.com>. Acesso em: abril, 2009.

FERRARA, L. Os lugares improváveis. In: YÁZIGI, E. Turismo e paisagem. São Paulo: Contexto, 2002. p. 65-82.

GAGLIARDI, P. Explorando o lado estético da vida organizacional. In: CLEGG, S. R.; HARDY, C.; NORD, W. R. (Orgs.). CALDAS, M.; FACHIN, R.; FISCHER, T. (Orgs. versão brasileira). Handbook de estudos organizacionais: reflexões e novas direções. v. 2, São Paulo: Atlas, 2002, p. 127- 149.

GALHANONE, R. F. Mercado do Luxo: Aspectos de Marketing. In: Anais...VIII SEMEAD - SEMINÁRIO DA ADMINISTRAÇÃO FEA USP, 2005, São Paulo. 2005, p. 1-16.

Galhanone, R. F.; TOlEDO, G. L. Comportamento do Consumidor de Produtos Luxuosos e Sofisticados: Um Estudo Empírico. In: Anais... XI SEMEAD, 2008, São Paulo. 2008, p. 1-12. 
GOBÉ, M. A emoção das marcas: conectando marcas às pessoas. Marc Gobé; tradução de Fluvio Lubisco. Rio de Janeiro: Campus, 2002.

HEISLEY, D. D.; LEVY, S. J. Autodriving: a Photoelecitation Technique. Chicago. Journal of Consumer Research, Chicago, IL, n. 18, p. 257-272, dec. 1991.

HETZEL, P. Lês approaches sócio-sémiotiques du design d'environment dês lieux de distribuition post- modernes. Études et Recherches sur la Distribution, Volle P. (ed.), Economia, Paris, p. 145- 166. 2000.

HOTEL FASANO. Fotos. Disponível em: <http://www.fasano.com.br>. Acesso em: abril, 2009.

HOTELNEWS. Pisos de Madeira: Revestimentos decorativos e duráveis. Revista Hotelnews: Hotelaria, Gastronomia, Tendências, n. 348, 2009.

KOEHL, J.-L. Le Marketing Sensoriel. Disponível em:

$<$ http://www.educnet.education.fr/ecogest/veille/mercatique/gc10>. Acesso em: 25/04/2004.

LAS CASAS, A. L. Marketing se Serviços. 2. ed. São Paulo: Atlas, 2000.

LHW. Leading Hotels of the World. Disponível em: <http://www.lhw.com>. Acesso em: abril, 2009.

LIPOVETSKY, G.; ROUX, E. O luxo eterno: da idade do sagrado ao tempo das marcas. São Paulo: Companhia das Letras, 2005.

MENDONÇA, J. R. C. de; BARBOSA, M. de L. A.; DURÃO, A. F. Fotografias como um Recurso de Pesquisa em Marketing: O Uso de Métodos Visuais no Estudo de Organizações de Serviços. RAC, v. 11, n. 3, Jul./Set. 2007. p. 57-81.

OLIVEIRA, A. de. Guru do Luxo: Entrevista com Carlos Ferreirinha. Revista Go Where Business, Ano I, n. 3, 2009.

PETR, C. La Gestion de L'expérience: De la recherche au controle. Décisions Marketing, Oct.-Dec., n. 28, 2002.

RIEUNIER S. Le marketing sensoriel du point de vente. Dunod: Paris, 2004.

SCHMITT, B; SIMONSON, C. O modelo das Experiências. HSM Management, Ano 4, n. 23, Nov.- Dez., 2002.

STREHLAU, S. O luxo falsificado e suas formas de consumo. 2004. 207 f. Tese de Doutorado ao Curso de Pós-graduação da Escola de Administração de Empresas de São Paulo da Fundação Getúlio Vargas, São Paulo, 2004. 
TEIXEIRA, A. K. G. O Sistema de Oferta de Restaurantes de Alta Gastronomia sob a Perspectiva Sensorial das Experiências de Consumo. Monografia (Bacharelado em Hotelaria). Departamento de Ciências Sociais Aplicadas, Universidade Federal de Pernambuco, Recife, 2007.

ZEITHAML, V.; BITNER, M. J. Marketing de serviço: a empresa com foco no cliente. 2. ed. Porto Alegre: Bookman, 2003.

Recebido em: 27-05-2013

Aceito para publicação em: 26-06-2013 